\section{Policies and Patterns in US For-Profit Higher Education}

\author{
Elizabeth Meza and William Zumeta
}

Elizabeth Meza is a research fellow and PhD candidate in higher education in the College of Education at the University of Washington. William Zumeta is professor of Public Affairs and Higher Education at the University of Washington. E-mail: zumeta@uw.edu and bapple@ uw.edu.

IHE regularly publishes articles on private higher education from PROPHE, the Program for Research on Private Higher Education, headquartered at the University at Albany. See http://www.albany.edu/.

For-profit institutions of higher education have become a 1 sizable component of the US higher education marketplace, yet they remain poorly documented in many respects and understudied. The growth of this sector in recent decades has been prodigious. As late as I995, the for-profit share of all students enrolled in postsecondary education was less than 2 percent. According to federal data, the private for-profit sector enrolled io percent of all students or around 2.I million, in 20I0. This is a conservative figure, counting only students enrolled at degree-granting institutions reporting to the government. The growth rates in this sector have skyrocketed since the mid-I990s-from 304,000 students in 1996 to 2,II0,000 in 2010-and their market share jumped from 2.I percent to Io percent. Federal policy has generally been accommodating: for-profit students are eligible for federal student aid grants and loans, and the schools have taken advantage of this aggressively.

Some for-profit institutions still reflect the origins of the sector in small, locally oriented, vocationally focused and often family-owned enterprises. Others have grown into corporate behemoths, encompassing virtually every postsecondary credential in vast portfolios of educational offerings (including graduate degrees) that in some cases transcend US borders. Some very recent contraction has been in the sector due to scandals over student recruiting practices and an increased public perception of low-quality, high-dropout rates. Also, a low-labor market returns for many degree holders (not to mention large debts incurred by both graduates and dropouts) during a period of extended labor-market sluggishness. Also, these concerns have led to increased regulatory pressure from the federal government.

Yet, it can be argued that this sector remains potentially important to the public interest, perhaps as never before. Around the world burgeoning growth is seen in private provision, as governments are increasingly unable to meet the demand for higher education utilizing public institutions alone, and the United States is not altogether different. Also of policy significance, the for-profit sector enrolls disproportionately large shares from groups of students-e.g., minorities, students of modest financial means, and those who are older than traditional college age-that are underrepresented elsewhere.

\section{The Role of State Policies}

We have recently researched state policies directed at forprofit higher education, since sector enrollment growth rates vary widely by state. In the United States, states have traditionally had the primary role in higher education policy. A majority of states now provide at least some student aid and/or other resources to the for-profit sector. States also have basic consumer protection and/or quality assurance responsibilities as part of their oversight of higher education within the US federal system. Moreover, in the modern, keenly competitive world, states have good reason to pay attention to all sources of capacity to educate their citizens and to the quality of what they provide.

\section{For-profit institutions of higher educa- tion have become a sizable component of the US higher education marketplace, yet they remain poorly documented in many respects and understudied.}

Variation in how states treat the for-profit industry has not been documented comprehensively; therefore, it is unknown whether the variation bears any relation to outcomes, in particular here for-profit enrollment growth rates. It has been interested in understanding the dramatic growth period from 2000-20I0. Using a variety of sources, we documented state policies toward for-profit institutions across several dimensions, to the extent possible given data limitations. These dimensions are: state student aid policy; direct state financial subventions to institutions for other purposes; rates of tuition change at public competitor institutions (assumed to be primarily public two-year colleges); involvement of the for-profit sector in state higher education governance and planning; nature and extent of information collection and dissemination about the sector; and intensity of state regulatory oversight and quality-assurance effort. Starting with Zumeta's (I996) conceptual model of state policy approaches or postures toward the private nonprofit sector, we found evidence that there are some distinct dif- 
ferences in how states view their for-profit sectors in terms of information policy, regulation, financial aid policy, and level of involvement in state higher education planning.

While not able to gather sufficient data to validate nuanced policy posture constructs, we could determine that states fall into two broad categories-displaying either laissez faire or active policies in regard to the degree to which they pay attention to for-profit higher education. There are serious measurement problems here, and most of our research had to rely on incomplete and sometimes impressionistic information gleaned from Web sites, selected phone interviews, and national data gathered for other purposes. We used definitions and distinctions that were found plausible given the information available rather than strictly defined and fully measured variables. After estimating the number of resident-in-state enrollments in for-profits in 2000 and 2010 (i.e., excluding primarily online enrollments in cases where the state of the student's residence cannot be determined), our fairly confident statement is that

\section{Using a variety of sources, we docu- mented state policies toward for-profit institutions across several dimensions, to the extent possible given data limita- tions.}

states that display active policy tend to be more populous, to have larger for-profit sector enrollment shares, and greater policy capacity. These states also showed significantly larger percentage growth in their for-profit enrollments relative to laissez-faire states. Rates of for-profit enrollment growth across the states, at least in the boom period of 2000-20I0, did not seem to be influenced by the contextual variables that influence nonprofit and public sector growth-i.e., state population growth or unemployment rates.

\section{These ReLATionships}

One possible conclusion is that, as initially hypothesized, state policy accounts for some of the variation in for-profit enrollment growth across states. Yet, there is also another possibility. Perhaps the causal arrow points the other waythe growth comes first and then elicits what Daniel C. Levy calls "reactive regulation," (i.e., active policy). Certainly, as the sector grows, policymakers may feel responsibility (and political pressure) to monitor it, perhaps seek to regulate it (i.e., for quality assurance or at least consumer protection), or utilize it to expand limited state educational capac- ity cheaply, and seek to further state workforce development goals. Private institutions, whether for-profit or nonprofit, surely have a role to play in meeting state and national needs for more educated people, if they provide a quality product. So, one needs to better understand the workings of policy systems in their sphere and the relationship of these workings to results. Enrollments, of course, are only a readily documented outcome of interest and perhaps not the most important one.

\section{Inside African Private High- er Education: Contradictions and Challenges}

\section{LOUISE MORLEY}

Louise Morley is professor in the Centre for Higher Education and Equity Research, University of Sussex, UK. E-mail: I.morley@sussex.ac.uk/ education.

T t would be erroneous to suggest that all quality challeng1 es reside in the private higher education sector in lowincome countries. Unfunded expansion and overall lack of human and material resources are also enemies of quality and standards throughout the public sector. However, it is pertinent to focus on the rapidly expanding private sector as now, worldwide. The rising social hunger for higher education and fiscal constraints have meant that the state, in many national locations, can no longer meet demands; and the private sector is seen as a response to capacity challenges in both developed and developing countries.

The market ideology of the private sector is often perceived as a contradiction to the core values of education for all, and critics fear that it will contribute to elite formation and social exclusions. Fears have tended to focus on the commodification of knowledge, the changing ethos, curriculum and values of higher education, a possible abdication of state responsibility, and the belief that new providers are compromising quality and standards by producing poorly regulated diploma mills. The private sector is also conceptualized as a threat to social diversity and equality of opportunity, with the potential to exclude students from low-socioeconomic backgrounds.

\section{Widening Participation in Higher Education in Ghana AND TANZANIA}

In a recent empirical study of Widening Participation in Higher Education in Ghana and Tanzania (http://www.sus- 